\title{
Growth inhibition of Fusarium solani and $F$. oxysporum by Streptomyces sasae TG01, and its ability to solubilize insoluble phosphate
}

\author{
I MADE SUDIANA", ADELIA PUTRI, TOGA PANGIHOTAN NAPITUPULU, IDRIS, ISMU PURNANINGSIH, \\ ATIT KANTI \\ Research Center for Biology, Indonesian Institute of Sciences. Cibinong Science Center, J1 Raya Jakarta Bogor Km. 46, Cibinong, Bogor 16911, West \\ Java, Indonesia. Tel.: +62-21-87907636, Fax.: +62-21-87907612, `email: imadesudianalipi@ gmail.com
}

Manuscript received: 11 November 2019. Revision accepted: 2 January 2020.

\begin{abstract}
Sudiana A, Putri A, Napitupulu TP, Purnaningsih I, Idris, Kanti A. 2020. Growth inhibition of Fusarium solani and F. oxysporum by Streptomyces sasae TG01, and its ability to solubilize insoluble phosphate. Biodiversitas 21: 429-435. Actinomycetes have been widely explored for new antibiotic production, but not many studies explore its abilities to inhibit the growth of phytopathogenic fungi and solubilize insoluble phosphate hence stimulate the growth of plants. We isolated Actinomycetes from the soil. Based on morphology, physiology, and $16 \mathrm{~S}$ rDNA analyses, the isolate is closely related to Streptomyces sasae. The strain was able to inhibit the growth of phytopathogenic fungi Fusarium solani, and Fusarium oxysporum. S. sasae produced secondary metabolites 2methyl-1,3-dioxolane as the major constituent. The strain assimilated variable carbon sources include L-arabinose, D-fructose, Dglucose, D-mannitol, Lactose, raffinose, L-rhamnose, and sucrose. The strain grew at pH 6.0 to 8.0, and at salinity (1-3\%). Their growth was affected by the salinity level. The strain solubilized Ca-P at 1-3\% salinity, but their ability to solubilize phosphate was influenced by salinity. The strain was also able to solubilize rock phosphate. Their ability to solubilize less soluble phosphate and inhibit the growth of $F$. solani and $F$. oxysporum may imply that this strain is potential for biocontrol agents. The 16S rRNA gene was submitted to DDBJ with the entry number 5df623c1a3c8820021322a36.TG01, and the accession number is LC514451.
\end{abstract}

Keywords: Antifungal activity, Fusarium solani, Streptomyces sasae TG1, rock phosphate

\section{INTRODUCTION}

Soil microbes have been explored to obtain many economically beneficial substances (van der Meij et al. 2017), and actinomycetes are a part of essential soil microbes. Culturing and isolating microbes include actinomycetes, has been a focus of microbiologist works. Our recent work is to explore the potential of soil microbes that can suppress the growth of Fusarium oxysporum, which is known as notorious plant disease, including banana (Musa acuminata). Banana is an economically important plant in Asia, include Indonesia. Banana is not only economically important plant, but also a part of Balinese culture since the banana is always included in traditional local offering (worship). However, recently, local banana suffers from banana wilt, most possibly caused by $F$. oxysporum. Several methods have been explored but none effective to suppress $F$. oxysporum and Fusarium solani.

Actinomycetes group have been traditionally explored to obtain antibiotics include antifungal (Basilio et al. 2003); many new antibiotics have been obtained. It is suspected that from that soil microbes, several secondary metabolites remain unexplored, especially to suppress the growth of $F$. solani and $F$. oxysporum. Earlier works have confirmed that the Actinomycetes group could be used as a biocontrol agent (Chen et al. 2018). Microbial consortia of bacteria and fungi could be effective in reducing the population of $F$. solani. Many pathogenic microbes may improve their resistance against antibiotics (Blair et al. 2015). F. oxysporum may alter their genetic characters and caused their resistance against fungicide or biocontrol agents (Forsberg et al. 2012), hence exploring the potential of microbes capable of inhibiting the growth of Foc (Fusarium oxysporum f. sp. cubense) is recommended.

Actinomycetes group and some species have been proposed as biocontrol agents for soil-borne plant diseases such as Streptomyces spp. Earlier studies observed that Streptomyces are biocontrol candidates for plant pathogenic fungi include Fusarium sp. (Gopalakrishnan et al. 2011), Colletotrichum sp. (Suwan et al. 2012), Rhizoctonia solani (Goudjal et al. 2014), and Sclerotium sp. (Jacob et al. 2018). The search for new antifungal compounds produced by the gram-positive bacteria with high DNA G+C contents also due to Actinomycetes has a broad ecological distribution covering from terrestrial, freshwater to marine environments. Actinomycetes have been contributing to the global antibiotic market, and the genus Streptomyces is the most popular wide spectrum antibiotic producer (Atta 2015). Well-known antibiotics having wide spectrum activity are erythromycin, gentamicin, rifamycin, and streptomycin ( Imai et al. 2012; Chaudhary et al. 2017).

Earlier studies found several mechanisms could be involved in the growth inhibition of soil born phytopathogens, which include the production of volatile organic compounds that enhance induce system resistance of host plants (Ryu et al. 2004). There are several mechanisms biocontrol agents suppress the growth of $F$. 
oxysporum, which include hyperparasitism (Heydari and Pessarakli 2010), antibiotic production, hydrolytic enzymes (Elad 2000), and protein toxin production (O’Brien 2017), as well as substrate competitions. Antibacterial and enzyme that were produced by Streptomyces spp. have played an essential role as plant growth promoters and controlling soil-borne plant pathogens (Shiva et al. 2018). Exploring the new biological control of plant pathogens is to reduce the environmental hazard of pesticides. Hence much effort should be devoted to the isolation of actinomycetes from natural resources, screen for their functional role, and characterization of their secondary metabolites to explore the maximum potential of the isolates. Efficacy of antibiotic and enzymes produced by actinomycetes depend on several factors, including bioactive compounds that they are produced.

Research on the use of actinobacteria as a biocontrol agent, as well as plant growth-promoting agents are getting popular. Actinomycetes affect the growth plant indirectly through controlling and minimizing the deleterious effects of abiotic and biotic stressor production of low molecular inhibitory substances such as ammonia, cyanogen, alcohols, aldehydes, sulfides, and ketones, cell-wall degrading enzymes, and secondary metabolites with biocidal properties (Sathya et al. 2017).

We isolated actinomycetes on the soil to find bioactive compounds that may be useful as an antibiotic, biocontrol of fungal pathogen. The objective of the study was to isolate and evaluate the ability of Streptomyces to inhibit the growth of Fusarium oxysporum and Fusarium solani and assess their potential as a plant growth promoter.

\section{MATERIALS AND METHODS}

\section{Isolation of actinomycetes}

Actinomycetes were isolated from ultisol soil of marginal land at Cibinong Science Center following the methods described by Kumar and Jadeja (2016). The site was selected $\left(6^{\circ} 29^{\prime} 26.0^{\prime \prime} \mathrm{S} 106^{\circ} 51^{\prime} 05.0 " \mathrm{E}\right)$ due to the soil was nutrient deficient with the total carbon of $1.8 \%(\mathrm{w} / \mathrm{w})$ and total nitrogen of $0.2 \%(\mathrm{w} / \mathrm{w})$. The soil sample was airdried in the oven at $80{ }^{\circ} \mathrm{C}$ for $24 \mathrm{~h}$, then the dilution series of soil samples were prepared. About $100 \mu \mathrm{L}$ of diluted soil suspension was spread on Humic Acid Vitamin (HV) agar medium supplemented with cycloheximide $\left(50 \mathrm{mg} \mathrm{L}^{-1}\right)$ and nalidixic acid $\left(20 \mathrm{mg} \mathrm{L}^{-1}\right)$. The plates were incubated at 30 ${ }^{\circ} \mathrm{C}$ for ten days. The colony of actinomycetes appeared then pick out and purified by repeated streaking on yeast extract-starch agar (YSA) medium and incubated at $30{ }^{\circ} \mathrm{C}$ for 14 days. The pure cultures of actinomycetes were preserved in glycerol $10 \%$ at- $80{ }^{\circ} \mathrm{C}$.

\section{Screening of actinomycetes isolates for antifungal activity}

The antifungal screening was performed against two pathogenic fungi $F$. solani (InaCC F76), F. oxysporum (InaCC F78) as the test fungi. These test fungi obtained from Indonesian Culture Collection (InaCC), Indonesian Institute of Science. The fungi were maintained on potato dextrose agar (PDA). The antifungal activity of actinomycetes isolates was performed by the dual culture method (Baharlouei and Bonjar 2011). About $6 \mathrm{~mm}$ mycelial discs from five days old PDA cultures of each test fungal pathogen were placed on the center of the Petri plate. Then, a $6 \mathrm{~mm}$ diameter of each isolate of actinomycetes 7 days old was placed onto the side of that petri dish about $1.5 \mathrm{~cm}$ away from the fungal colony. The plates were incubated at $30{ }^{\circ} \mathrm{C}$ for $7-14$ days. The inhibition was determined by measuring the distance between the edges of the fungal mycelia and the actinomycetes then compared with control (fungus was growth into PDA media without actinomycetes), and the result was presented in percent inhibition.

\section{Extraction of bioactive compounds and determination of secondary metabolites}

The secondary metabolites were analyzed using Gas chromatography, and Mass Spectrometry (GC-MS) in the crude extract of isolate TG01 analysis was performed to identify the chemical compounds. First, the crude extract of isolate TG01 was extracted by ethyl acetate extraction method (Sengupta et al. 2015). The culture was grown in Yeast Starch Broth (YSB) for five days in a shaker incubator at $30{ }^{\circ} \mathrm{C}$. After the incubation period, the culture broth was centrifuged at $8000 \mathrm{rpm}$ for 15 minutes. The supernatant was collected and mixed with an equal volume of ethyl acetate. The upper phase was transferred into a 50 $\mathrm{mL}$ round bottom flask. The extracted crude compound was evaporated in a rotary evaporator at $40{ }^{\circ} \mathrm{C}$. The crude extract was solved in $1 \mathrm{~mL}$ ethyl acetate: acetone: methanol (1: 1: 1) and centrifuged at $14000 \mathrm{rpm}$ for 10 minutes. Then, the active eluent compounds were identified by gas chromatography and mass spectrometry (GC-MS) method (Nandhini et al. 2015). The mass spectrum was recorded using AGILENT GC-MS 5975C with temperature program of $70-300{ }^{\circ} \mathrm{C}, 10^{\circ} \mathrm{C} \mathrm{min}^{-1}$, injection temperature $=240{ }^{\circ} \mathrm{C}$, carrier gas $=$ helium, flow rate $=1.51 \mathrm{ml} \mathrm{min}^{-1}$.

\section{Morphological and physiological characteristics}

The culture characterization of Streptomyces sasae TG01 was examined according to the method (Aouar and Boulahrouf 2012; Wink 2016). Morphological characteristics of the isolate were done in various media, including yeast extract-malt extract agar (ISP 2), oatmeal agar (ISP 3), starch agar (ISP 4), glycerol-asparagine agar (ISP 5), and yeast starch agar (YSA). The colony characteristic was observed using a microplate technique in which a six-well plate was used. One $\mathrm{ml}$ of the shaking culture of isolate TG01 7 days old was plated onto the plates of these media. Then, the plated was incubated at 30 ${ }^{\circ} \mathrm{C}$ for 7-14 days. Spore surface ornamentation was determined by scanning electron microscopy from 21-28 days old culture on yeast malt extract agar.

The optimal $\mathrm{pH}$ of growth of this isolate was tested in medium slant agar ISP 2 was adjusted to $\mathrm{pH} 4-10$ with added $0.1 \mathrm{~N} \mathrm{HCl}$ and $0.1 \mathrm{~N} \mathrm{NaOH}$. Seven days old isolate TG01 was streak in each medium slant. The isolate was growth on ISP 2 medium containing each $1.0 \%-5.0 \%$ of sodium chloride in microplate with six-well plates to test the resistance toward sodium chloride. The growth of 
isolate on medium ISP2 containing each $\mathrm{pH}$ and $\mathrm{NaCl}$ observed after 7-14 days incubation.

The ability of the isolate to use various carbon sources was tested in a microplate with 12 well. The carbon sources used were fructose, glucose, lactose, and sucrose. Glucose as a positive control and basal medium without carbon source as a negative control. 1\% solution of each carbon added to the basal medium after the medium autoclaving and cooling to $60{ }^{\circ} \mathrm{C}$. Five $\mathrm{ml}$ of medium with $1 \%$ each carbon source were plated in a microplate, then $200 \mu \mathrm{L}$ shaking culture seven days old was plated into each well plate. The plate was incubated at $30{ }^{\circ} \mathrm{C}$ for 7-14 days. The growth of the colony on each well was compared with the positive and negative control.

\section{Molecular identification}

Genomic DNA was extracted according to (FrancoCorrea et al. 2010) method. The $16 \mathrm{~S}$ rRNA gene was amplified by PCR using Takara Taq with primer 27F (5' AgAGTTTGA TCMTGGCTCAG $\left.3^{\prime}\right)$ and 1492R (5' TACGGYTACCTTGTTACGACTT 3'). The cyclic condition was as follows: initial denaturation at $94{ }^{\circ} \mathrm{C}$ for 90 seconds, 35 cycles of $95{ }^{\circ} \mathrm{C}$ for 30 seconds, $55^{\circ} \mathrm{C}$ for 30 seconds, and $72{ }^{\circ} \mathrm{C}$ for 90 seconds, and a final extension at $72{ }^{\circ} \mathrm{C}$ for 10 minutes and hold at $4{ }^{\circ} \mathrm{C}$. The polymerase PCR was confirmed by $1 \%$ agarose gel electrophoresis. Then, the $16 \mathrm{~S}$ rRNA gene was sequenced. The $16 \mathrm{~S}$ rRNA gene sequenced was compared with other sequences in the Eztaxon-e server (Kim et al. 2012). Specifically, the $16 \mathrm{~S}$ rRNA gene sequenced obtained were aligned with the reference sequence of known species in a genus using CLUSTAL W.

\section{Phosphate solubilization}

Optimization of the carbon sources condition

After screening of the solubilization insoluble phosphate characteristic, a strain with the most ability was

Table 1. Modified Pikovskaya medium with a different combination of phosphate sources and carbon sources.

\begin{tabular}{lc}
\hline Ingredients & g L-1 \\
\hline Yeast extract & 0.500 \\
Carbon source & 10.000 \\
(Glucose/lactose/sucrose/fructose/starch) & \\
Phosphate source (tricalcium phosphate/rock & 5.000 \\
phosphate) & \\
Ammonium sulfate & 0.500 \\
Potassium chloride & 0.200 \\
Magnesium sulfate & 0.100 \\
Manganese sulfate & 0.0001 \\
Ferrous sulfate & 0.0001 \\
NaCl (adjusted to\% w/v) & $1,2,3,4$ \\
\hline
\end{tabular}

chosen. The optimization of the phosphorus solubilization was done on $200 \mathrm{~mL}$ of modified Pikovskaya broth medium in 500-mL conical flasks (Table 1) in different combinations of phosphate sources and carbon sources. The conical flask was shaken at $120 \mathrm{rpm}$ in room temperature for seven days. Then, spores and mycelia of the selected strain were separated from broth culture by centrifugation at $8,000 \mathrm{rpm}$ for $10 \mathrm{~min}$. The supernatant of each culture was analyzed for phosphate concentration.

\section{Quantitative determination of phosphate concentration}

A spectrophotometric method with some modifications was implemented to estimate phosphate concentration in the uninoculated control and supernatant. One $\mathrm{mL}$ culture supernatant was mixed with $3 \mathrm{~mL}$ of distilled water and 1 $\mathrm{mL}$ of color reagent containing ammonium molybdate ( $\left.\left(\mathrm{NH}_{4}\right)_{6} \mathrm{Mo}_{7} \mathrm{O}_{24} \cdot 4 \mathrm{H}_{2} \mathrm{O}\right) \quad 1.5 \%(\mathrm{w} / \mathrm{v})$, sulfuric acid $\left(\mathrm{H}_{2} \mathrm{SO}_{4}\right)$ solution $5.5 \%(\mathrm{v} / \mathrm{v})$ and ferrous sulfate $\left(\mathrm{FeSO}_{4}\right)$ solution $2.7 \%(\mathrm{w} / \mathrm{v})$ in a reaction tube. The mixture was vigorously shaken for 5 seconds then measured by a UV-Vis spectrophotometer (JK-VS-721N, JKI, China) at $600 \mathrm{~nm}$. The same procedure was applied to control. The level of phosphate concentration was determined by using a standard graph of potassium dihydrogen phosphate $\left(\mathrm{KH}_{2} \mathrm{PO}_{4}\right)$ and expressed as $\mathrm{H}_{2} \mathrm{PO}_{4}{ }^{-}$concentration in $\mu \mathrm{g} \mathrm{mL}-$ ${ }_{1}^{1}$ after correction with $\mathrm{H}_{2} \mathrm{PO}_{4}{ }^{-}$concentration in uninoculated control.

\section{RESULTS AND DISCUSSION}

\section{Antifungal activity of Actinomycetes isolates}

A total of 15 isolates were isolated from soil, only five isolates inhibited $F$. solani, seven isolates inhibited the growth of $F$. oxysporum, and one isolate (TG01) inhibited the growth of $F$. solani and $F$. oxysporum (Table 2). Isolate TG01 was chosen for further study.

Table 2. Inhibition of Fusarium solani, and F. oxysporum by Actinomycetes isolates

\begin{tabular}{|c|c|c|}
\hline \multirow[b]{2}{*}{ Isolates code } & \multicolumn{2}{|c|}{ Growth inhibition against } \\
\hline & $\begin{array}{c}\text { F. solani } \\
(\text { InaCC F76) }\end{array}$ & $\begin{array}{r}\text { F. oxysporum } \\
(\text { InaCC F78) }\end{array}$ \\
\hline TG 001 & + & + \\
\hline TG 002 & - & + \\
\hline TG 003 & + & - \\
\hline TG 004 & + & - \\
\hline TG 005 & - & + \\
\hline TG 006 & + & - \\
\hline TG 007 & - & + \\
\hline TG 008 & - & + \\
\hline TG 009 & + & - \\
\hline TG 010 & - & + \\
\hline TG 111 & - & - \\
\hline TG 112 & - & + \\
\hline TG 113 & - & - \\
\hline TG 114 & - & - \\
\hline TG 115 & - & - \\
\hline
\end{tabular}

Note:-, no inhibition, and + the inhibition was about $10-20 \%$ 


\section{Morphological and physiological characteristics of Actinomycetes isolate TG01}

The morphological characteristic of isolate TG01 was observed after 14-28 days of growth on five different media on microplate with six-well. Isolate TG01 grew good on YSA, ISP 2, ISP 3, and ISP 4 media and grew moderate on ISP 5 medium. The color of the colony was yellow on YSA, ISP 2, ISP 3, and ISP 4 and grey on ISP 5. The isolate formed white or basal gray aerial mycelium on YSA, ISP2, ISP3, and ISP 4 and no aerial mycelium observed on ISP5 (Table 3). The color of the substrate mycelium was white. The isolate produced diffusible pigment into media YSA, ISP2, ISP3, and ISP 4, but did not produce into ISP 5.

The ability of Actinomycetes to survive in the soil is influenced by their ability to use various carbon sources. The isolated TG01 was able to use different carbon sources and tolerate a wide range of salinity (1-5\%), as was shown in Table 3. The carbon assimilation pattern and preferability of microbes to use a specific are related to their ability to survive in various environmental conditions. An earlier study on Escherichia coli observed that glucose, lactose, fructose, glycerol is the preferable substrate. Glucose and lactose are both highly preferable carbon sources for $E$. coli, both supporting large growth rates. Fructose, glycerol, maltose, and galactose are less preferred (Wang et al. 2019), but isolate TG01 can use fructose as good as glucose.

For the case of Actinomycetes, the selection of carbon and nitrogen sources affects secondary metabolite production. For instance, Streptomyces kanamyceticus ATCC 12853 produces high kanamycin when galactose used as a carbon source while dextrin, soluble starch, and potato starch gave moderate yields. Best nitrogen sources are sodium nitrate, and glycine were the best nitrogen sources for kanamycin production. Kanamycin production was best at alkaline pH (Pandey et al. 2005). Carbon sources also influenced antifungal production by Streptomyces hygroscopicus as indicated by optimal Altenaria growth inhibition when $S$. hygroscopicus has grown on fructose and starch. The isolate TG01 can grow at various carbon sources include D-arabinose, F-fructose, raffinose, L-rhamnose, sucrose, glucose, and they can grow till $40{ }^{\circ} \mathrm{C}$ (Table 4$)$.

\section{Molecular identification of Actinomycetes isolates}

The isolate TG01 belongs to $S$. sasae based on the $16 \mathrm{~S}$ rRNA gene sequence and blast analysis. This sequence showed its similarity to many species of the genus Streptomyces. It was $99.38 \%$ similar to S. sasae JR-39 (HQ267987), 99.14 similar to Streptomyces panaciradicis 1MR-8 (KF971876), 98.78\% identical to Streptomyces capoamus JCM 4734 (AB045877) and 98-99\% identical to other species in the genus Streptomyces.

\section{Secondary metabolite analysis}

Streptomyces sasae TG01 produced various secondary metabolites. The secondary metabolites were mainly composed of 7 compounds (Table 5). The major constituent was 2-methyl-1,3-dioxolane. This compound was potential as a growth inhibitor of C. albicans, Staphylococcus aureus, S. epidermidis, Enterobacter faecalis, and Pseudomonas aeruginosa (Gul and Bakht 2015).

Table 4. Some morphological and physiological characters of isolates TG01

\begin{tabular}{ll}
\hline Characteristic & Isolate TG01 \\
\hline Aerial spore mass color on ISP 2 & Grey \\
Reserve side of the colony on ISP 2 & light yellow \\
Diffusible pigment & Produce \\
Spore chain & coil spiral \\
Growth at/ with $\mathrm{NaCl}(\%, \mathrm{w} / \mathrm{v})$ & \\
$\mathrm{NaCl} 1.0 \%$ & + \\
$\mathrm{NaCl} 2.0 \%$ & + \\
$\mathrm{NaCl} 3.0 \%$ & + \\
$\mathrm{NaCl} 5 . \%$ & - \\
Growth at pH & $6-8$ \\
$\mathrm{pH} 6$ & + \\
$\mathrm{pH} 7$ & + \\
$\mathrm{pH} 8$ & + \\
$\mathrm{Growth}$ at temperature & \\
$30^{\circ} \mathrm{C}$ & + \\
$35^{\circ} \mathrm{C}$ & + \\
$40^{\circ} \mathrm{C}$ & + \\
$45^{\circ} \mathrm{C}$ & - \\
Carbon utilization & \\
$\mathrm{D}-$ arabinose & + \\
F-fructose & + \\
Raffinose & + \\
L-rhamnose & + \\
Sucrose & + \\
Glucose & + \\
Lactose & + \\
\hline
\end{tabular}

Table 3. Cultural characteristics of isolate TG01

\begin{tabular}{|c|c|c|c|c|c|}
\hline \multirow{2}{*}{ Characteristic } & \multicolumn{5}{|c|}{ Isolate TG01 } \\
\hline & YSA & ISP 2 & ISP 3 & ISP 4 & ISP 5 \\
\hline Growth & Good & Good & Good & Good & Moderate \\
\hline Colour of substrate mycelium & White & White & White & White & White \\
\hline Colour of aerial mycelium & Grey & Grey & Grey & Grey & - \\
\hline Sporulation & Good & Good & Better & Good & - \\
\hline Produce diffusible pigment & Produced & Produced & Produced & Produced & Did not produce \\
\hline Colour of diffusible pigment & Yellow & Yellow & Yellow & Yellow & - \\
\hline
\end{tabular}


Table 5. Bioactive compounds of S. sasae TG01 identified by GC-MS analysis

\begin{tabular}{lcccc}
\hline Name of compound & Molecular formula & Molecular weight & Retention time & Area\% \\
\hline Undecane & $\mathrm{C}_{11} \mathrm{H}_{24}$ & 156.3 & 8.294 & 5.12 \\
2-propyl-1-pentanol & $\mathrm{C}_{8} \mathrm{H}_{18} \mathrm{O}$ & 130.2 & 9.85 & 6.50 \\
tetra-butylbenzene & $\mathrm{C}_{10} \mathrm{H}_{14}$ & 134.2 & 9.944 & 3.74 \\
Undecane & $\mathrm{C}_{11} \mathrm{H}_{24}$ & 156.3 & 10.332 & 5.76 \\
1,2,4,5-tetramethyl benzene & $\mathrm{C}_{10} \mathrm{H}_{14}$ & 134.2 & 13.442 & 2.38 \\
(e)-3-tetradecane & $\mathrm{C}_{14} \mathrm{H}_{28}$ & 196.8 & 31.352 \\
2-methyl-1,3-dioxolane & $\mathrm{C}_{4} \mathrm{H}_{8} \mathrm{O}_{2}$ & 88.106 & 55.97 \\
\hline
\end{tabular}

Some compounds were identified by GC-MS analysis also presented in the extract of marine Streptomyces ( Sudha and Masilamani 2012; Nandhini et al. 2015), extract of Streptomyces anulatus (El-naggar et al. 2017), extract of Streptomyces SCA 7 (Saravana et al. 2014), and extract of Trichoderma atroviride (Keszler et al. 2000). Streptomyces sp. ability to produce many kinds of antibiotics and have been recognized as a producer of bioactive metabolites with wide-spectrum activity (7) Some of the compounds that have been reported had an antimicrobial activity such as dodecane and phenol 2,4 bis (1,1-dimethyl) ( Sudha and Masilamani 2012; Kumar et al. 2014; Saravana et al. 2014; Nandhini et al. 2015). Kumar et al. (2014) reported that out of 7 compounds produced by Streptomyces SCA 7 ( Kumar et al. 2014), the phenol 2,4 bis (1,1-dimethyl) compound had the highest antimicrobial activity.

Solubilization of phosphate by Streptomyces sasae TG01 under various carbon sources and salinity

$S$. sasae TG01 was phosphate solubilizing Actinomycetes, and their ability to solubilize phosphate was variable depending on carbon sources (Table 6).

$S$. sasae TG01 was able to solubilize $\mathrm{P}$ at various concentrations of $\mathrm{NaCl}$. The highest P-solubilization was observed at $1-3 \%$, but lower P-solubilization was observed at $4.0 \% \mathrm{NaCl}$. The strain was able to solubilize both Ca-P and rock phosphate under saline conditions. The best carbon source for P-solubilization was glucose and lactose, followed by sucrose, fructose, and starch. In general, Phosphate solubilizing capacity influenced by salinity was previously observed by Srinivasan (Srinivas et al. 2012). They found Aerococcus sp. strain PSBCRG 1-1 and Pseudomonas aeruginosa strain PSBI 3-1 was able to grow and solubilize $\mathrm{Ca}-\mathrm{P}$ at $0.4 \mathrm{M} \mathrm{NaCl}$, but at higher salinity $\mathrm{P}$ solubilization capacity was retarded. In the case of fungi (Aspergillus terreus strain PSFCRG 2-1), they can tolerate higher $\mathrm{NaCl}(0.8 \mathrm{M})$, and $\mathrm{P}$-solubilization was much higher (12.12\% equal approximately about $76.36 \mathrm{mg}-\mathrm{P} \mathrm{L}^{-1}$ ). Higher P-solubilization was reported by Aspergillus sp. strain PSFNRH-2 (20.81\%, approximately $131.10 \mathrm{mg}-\mathrm{P} \mathrm{L}^{-}$ $\left.{ }^{1}\right)$. Ca-P solubilization by the last strain was not affected by salinity. They observed that it was at 7-d and decline after 15 days after incubation. Enterobacter hormaechei NUU10, plant growth-promoting microorganism, was able to stimulate the growth of Tomato both in saline and nonsaline soil from the rhizosphere of Tomato (Egamberdieva et al. 2014). S. sasae TG01 solubilize P less than those microbes, but $S$. sasae TG01 inhibits $F$. solani and Fusarium oxysporum, which may indicate that $S$. sasae TG01 could be potential biocontrol, as well as plant growth-promoting microbes.

Table 6. Solubilization of insoluble phosphate at various carbon sources and salinity by Streptomyces sasae TG01

\begin{tabular}{|c|c|c|c|c|}
\hline \multirow{2}{*}{ Carbon sources } & \multicolumn{4}{|c|}{ Sodium chloride $(\%$ w/v) } \\
\hline & $1.0 \%$ & $2.0 \%$ & $3.0 \%$ & $4.0 \%$ \\
\hline \multicolumn{5}{|l|}{ Glucose } \\
\hline $\mathrm{Ca}_{3}\left(\mathrm{PO}_{4}\right)_{2}$ & $22.41 \pm 2.52$ & $25.68 \pm 3.56$ & $18.56 \pm 3.12$ & $7.43 \pm 1.86$ \\
\hline Rock phosphate & $7.43 \pm 1.98$ & $8.41 \pm 2.62$ & $5.41 \pm 1.72$ & $2.41 \pm 1.11$ \\
\hline \multicolumn{5}{|l|}{ Sucrose } \\
\hline $\mathrm{Ca}_{3}\left(\mathrm{PO}_{4}\right)_{2}$ & $15.35 \pm 2.73$ & $21.68 \pm 4.2$ & $13.64 \pm 2.97$ & $5.97 \pm 2.14$ \\
\hline Rock phosphate & $7.46 \pm 1.98$ & $7.49 \pm 1.52$ & $5.41 \pm 1.64$ & $1.17 \pm 0.63$ \\
\hline \multicolumn{5}{|l|}{ Lactose } \\
\hline $\mathrm{Ca}_{3}\left(\mathrm{PO}_{4}\right)_{2}$ & $22.49 \pm 2.52$ & $25.68 \pm 3.56$ & $18.56 \pm 3.12$ & $7.43 \pm 2.14$ \\
\hline Rock phosphate & $3.46 \pm 1.17$ & $6.92 \pm 1.98$ & $4.91 \pm 1.25$ & $2.85 \pm 1.37$ \\
\hline \multicolumn{5}{|l|}{ Fructose } \\
\hline $\mathrm{Ca}_{3}\left(\mathrm{PO}_{4}\right)_{2}$ & $12.34 \pm 1.62$ & $15.36 \pm 2.22$ & $13.56 \pm 3.12$ & $6.32 \pm 1.76$ \\
\hline Rock phosphate & $4.93 \pm 1.98$ & $4.31 \pm 1.65$ & $3.72 \pm 1.47$ & $1.91 \pm 0.81$ \\
\hline \multicolumn{5}{|l|}{ Starch } \\
\hline $\mathrm{Ca}_{3}\left(\mathrm{PO}_{4}\right)_{2}$ & $9.19 \pm 1.78$ & $11.72 \pm 2.17$ & $10.11 \pm 2.93$ & $4.24 \pm 1.83$ \\
\hline Rock phosphate & $3.16 \pm 0.87$ & $4.11 \pm 1.98$ & $4.67 \pm 2.95$ & $3.15 \pm 1.92$ \\
\hline
\end{tabular}


Phosphate solubilizing and IAA producing rhizobacteria increase plant adaptability under salinity stress. The work of Kadmiri (2018), who introduced Pseudomonas fluorescens Ms-01 and Azosprillum brasilense DSM1690, succeed to enhance wheat productivity in saline soil. Those microbes were able to solubilize Ca-P even at the solution with salinity $600 \mathrm{mM}$ $\mathrm{NaCl}$. The mechanism by which microbes can enhance plant salt tolerance is well understood, one mechanism possible through increased proline accumulation and antioxidant enzymes activities improved enhance and hence lead to better plant defense pathway against salt stress (Kadmiri et al. 2018). The ability of $S$. sasae TG01 to inhibit growth $F$. solani and $F$. oxysporum solubilize phosphate under saline condition enrich the diversity of microbes for enhancing the growth of plant under abiotic stress.

The information on the utilization of $S$. sasae as a biocontrol agent for suppressing the growth of $F$. solani and $F$. oxysporum as well as stimulate $\mathrm{Ca}-\mathrm{P}$ solubilization under saline condition increase the value of our collection for sustainable development on agricultures. In conclusion, $S$. sasae TG01 produce antifungal mainly 2-methyl-1,3dioxolane as the major constituent and able to solubilize $\mathrm{Ca}-\mathrm{P}$ under saline condition implies that the isolate could be potential for biocontrol agent and promote plant growth.

\section{ACKNOWLEDGEMENTS}

The author gratefully to thank the Ministry of Research and Technology and Higher Education for the INSINAS research grant for research funding. The author also would like to thank Mia Kusmiati, Dian Alfian, and Gita Azizah Putri from Research Center for Biology, Indonesian Institute of Sciences for help during the research period, and all members, who have been helped to collect the samples.

\section{REFERENCES}

Aouar L, Boulahrouf A. 2012. Taxonomic identification of rhizospheric actinobacteria isolated from Algerian semi-arid soil exhibiting antagonistic activities against plant fungal pathogens. Can J Plant Pathol 34 (2): 165-176. DOI: 10.1080/07060661.2012.681396

Atta HM. 2015. Biochemical studies on antibiotic production from Streptomyces sp .: Taxonomy, fermentation, isolation, and biological properties. J Saudi Chem Soc 19 (1): 12-22. DOI: 10.1016/j.jscs.2011.12.011

Baharlouei A, Bonjar GHS. 2011. Biological control of Sclerotinia sclerotiorum (oilseed rape isolate) by an effective antagonis Streptomyces. Afr J Biotechnol 10 (30): 5785-5794. DOI: 10.5897/AJB10.2017

Basilio A, González I, Vicente MF, Gorrochategui J, Cabello A, González A, Genilloud O. 2003. Patterns of antimicrobial activities from soil actinomycetes isolated under different conditions of $\mathrm{pH}$ and salinity. J Appl Microbiol 2003;95: 814-823. DOI: 10.1046/j.13652672.2003.02049.x

Blair JMA, Webber MA, Baylay AJ, Ogbolu DO, Piddock LJV. 2015 Molecular mechanisms of antibiotic resistance. Nat Rev Microbiol 13: 2-51. DOI: $10.1038 /$ nrmicro3380

Chaudhary HS, Soni B, Shrivastava AR, Shrivastava S. 2017. Diversity and versatility of actinomycetes and its role in antibiotic production.
Appl Pharm Sci 3 (8 Suppl 1): S83-S94. DOI: 10.7324/JAPS.2013.38.S14

Chen Y, Zhou D, Qi D, Gao Z, Xie J. 2018. Growth promotion and disease suppression ability of a Streptomyces sp. CB-75 from banana rhizosphere soil. Front Microbiol 8 (2704): 1-18. DOI: 10.3389/fmicb.2017.02704

Egamberdieva D, Botir H, Abeer H, Abd-Allah E F. 2014. Characterization of salt-tolerant Enterobacter hormaechei strain associated with tomato root grown in arid saline soil. J Pure Appl Microbiol 8 (5): 4231-4239

El-naggar NE, El-bindary AA, Abdel-M, Nour NS. 2017. In vitro activity, extraction, separation and structure elucidation of antibiotics produced by Streptomyces anulatus NEAE-94 active against multidrug-resistant Staphylococcus aureus. Biotechnol Biotec Eq 31 (2): 418-430. DOI: 10.1080/13102818.2016.1276412

Elad Y. 2000. Biological control of foliar pathogens by means of Trichoderma harzianum and potential modes of action. Crop Prot 19 (8-10): 709-714. DOI: 10.1016/S0261-2194 (00)00094-6

Forsberg KJ, Reyes A, Wang B, Selleck EM, Sommer MOA, Dantas G. 2012. The shared antibiotic resistome of soil bacteria and human pathogens. Science 337 (6098): 1107-1111. DOI: $10.1126 /$ science. 1220761

Franco-Correa M, Quintana A, Duque C, Suarez C, Rodríguez MX, Barea JM. 2010. Evaluation of actinomycete strains for key traits related with plant growth promotion and mycorrhiza helping activities. Appl Soil Ecol 45 (3): 209-217. DOI: 10.1016/j.apsoil.2010.04.007

Gopalakrishnan S., Pande S, Sharma M, et al. 2011. Evaluation of actinomycete isolates obtained from herbal vermicompost for the biological control of Fusarium wilt of chickpea. Crop Prot 30 (8): 1070-1078. DOI: 10.1016/j.cropro.2011.03.006

Goudjal Y, Toumatia O, Yekkour A, Sabaou N, Mathieu F, Zitouni A. 2014. Biocontrol of Rhizoctonia solani damping-off and promotion of tomato plant growth by endophytic actinomycetes isolated from native plants of Algerian Sahara. Microbiol Res 169 (1): 59-65. DOI: 10.1016/j.micres.2013.06.014

Gul P, Bakht J. 2015. Antimicrobial activity of turmeric extract and its potential use in food industry. J Food Sci Tech 52 (4): 2272-2279. DOI: $10.1007 / \mathrm{s} 13197-013-1195-4$

Heydari A, Pessarakli M. 2010. A review on biological control of fungal plant pathogens using microbial antagonists. J Biol Sci 10 (4): 273290. DOI: $10.3923 /$ jbs.2010.273.290

Imai Y, Fujiwara T, Ochi K, Hosaka T. 2012. Development of the ability to produce secondary metabolites in Streptomyces through the acquisition of erythromycin resistance. J Antibiot 65 (6): 323-326. DOI: $10.1038 /$ ja.2012.16

Jacob S, Sajjalaguddam RR, Sudini HK. 2018. Streptomyces sp. RP1A-12 mediated control of peanut stem rot caused by Sclerotium rolfsii. J Integ Agr 17 (4): 892-900. DOI: 10.1016/S2095-3119 (17)61816-1

Wink MJ. 2016. Methods for the taxonomic description of the Actinobacteria, 1-42. https: //doi.org/Retrieved from https: //www.dsmz.de/bacterial-diversity/compendium-of-actinobacteria

Kadmiri IM, Chaouqui L, Azaroual SE, Sijilmassi B, Yaakoubi K, Wahby I. 2018. Phosphate-Solubilizing and Auxin-Producing Rhizobacteria Promote Plant Growth Under Saline Conditions. Arab J Sci Eng 43 (7): 3403-3415. DOI: 10.1007/s13369-017-3042-9

Keszler Á, Forgács E, Kótai L, Vizcaíno JA, Monte E, García-acha I. 2000. Separation and identification of volatile components in the fermentation broth of Trichoderma atroviride by solid-phase extraction and gas chromatography-mass spectrometry. J Chromatogr Sci 38: 421-424.

Kim O, Cho Y, Lee K, Yoon S, Kim M, Na H, ... Chun J. 2012 Introducing EzTaxon-e: a prokaryotic 16S rRNA gene sequence database with phylotypes that represent uncultured species. Int J Syst Evol Microbiol 62: 716-721. DOI: 10.1099/ijs.0.038075-0

Kumar PS, Duraipandiyan V, Ignacimuthu S. 2014. Isolation, screening and partial purification of antimicrobial antibiotics from soil Streptomyces. Kaohsiung J Med Sci 30 (9): 435-446. DOI: 10.1016/j.kjms.2014.05.006

Kumar RR, Jadeja VJ. 2016. Isolation of Actinomycetes: A Complete Approach. Int J Curr Microbiol Appl Sci 201;5 (5): 606-618. DOI: 10.20546/ijcmas.2016.505.062

Lee H, Whang K. 2015. Streptomyces sasae sp. nov ., isolated from bamboo ( Sasa borealis ) rhizosphere soil. Int J Syst Evol Microbiol 65: 3547-3551. DOI: 10.1099/ijsem.0.000454 
Nandhini U, Sangareshwari S, Lata K. 2015. Gas chromatography-mass spectrometry analysis of bioactive constituents from the marine Streptomyces. Asian J of Pharm Clin Res 8 (2): 6-8.

O'Brien PA. 2017. Biological control of plant diseases. Australas Plant Path 2017;46 (4): 293-304. DOI: 10.1007/s13313-017-0481-4

Pandey A, Shukla A, Majumdar SK. 2005. Utilization of carbon and nitrogen sources by Streptomyces kanamyceticus M 27 for the production of an antibacterial antibiotic. Afri J Biotechnol 4 (9): 909910 http: //www.academicjournals.org/AJB

Ryu CM, Farag MA, Hu CH, Reddy MS, Kloepper JW, Paré. 2004 Bacterial volatiles induces systemic resistance in Arabidopsis. Plant Physiol 134 (3): 1017-1026. DOI: 10.1104/pp.103.026583

Sadeghi A, Soltani BM, Jouzani GS, Karimi E, Nekouei MK Sadeghizadeh M. 2014. Taxonomic study of salt tolerant Streptomyces sp. strain C-2012 and the effect of salt and ectoine on lon expression level. Microbiol Res 169 (2-3): 232-238. DOI: 10.1016/j.micres.2013.06.010

Saravana KP, Duraipandiyan V, Ignacimuthu S. 2014. Isolation, screening and partial purification of antimicrobial antibiotics from soil Streptomyces sp. SCA 7. Kaohsiung J Med Sci 30 (9): 435-46. DOI: 10.1016/j.kjms.2014.05.006

Sathya A, Vijayabharathi R, Gopalakrishnan S. 2017. Plant growthpromoting actinobacteria: a new strategy for enhancing sustainable production and protection of grain legumes. 3 Biotech 7: 102. DOI: $10.1007 /$ s13205-017-0736-3
Sengupta S, Pramanik A, Ghosh A, Bhattacharyya M. 2015. Antimicrobial activities of actinomycetes isolated from unexplored regions of Sundarbans mangrove ecosystem. BMC Microbiol 15 (170). DOI: 10.1186/s12866-015-0495-4

Shiva S, Prasad K, Giovanardi D, Stefani E. 2018. Plant growthpromoting and biocontrol activity of Streptomyces spp . as endophytes. Int J Mol Sci 19: 1-26. DOI: /10.3390/ijms19040952

Srinivasan R, Yandigeri MS, Kashyap S, Alagawadi AR. 2012. Effect of salt on survival and P-solubilization potential of phosphate solubilizing microorganisms from salt-affected soils. Saudi J Biol Sci 19 (4): 427-434. DOI: 10.1016/j.sjbs.2012.05.004

Sudha S, Masilamani SM. 2012. Characterization of cytotoxic compounds from marine sediment derived actinomycete Streptomyces avidinii strain SU4. Asian Pac J Trop Biomed 2 (10): 770-3. DOI: 10.1016/S2221-1691 (12)60227-5

Suwan N, Boonying W, Nalumpang S. 2012. Antifungal activity of soil actinomycetes to control chilli anthracnose caused by Colletotrichum gloeosporioides. J Agr Technol 8 (2): 725-737.

van der Meij A, Worsley SF, Hutchings MI, van Wezel GP. 2017. Chemical ecology of antibiotic production by actinomycetes. FEMS Microbiol Rev 41 (3): 392-416. DOI: 10.1093/femsre/fux005

Wang X, Xia K, Yang X, Tang C. 2019. Growth strategy of microbes on mixed carbon sources. Nature Commun 10: 1279. DOI: 10.1038/s41467-019-09261-3 